\title{
Influence of Degree of Dispersion of Noncovalent Functionalized Graphene Nanoplatelets on Rheological Behaviour of Aqueous Drilling Fluids
}

\author{
Arif Ibrahim $(\mathbb{D}$, Syahrir Ridha $(\mathbb{D}$, Asna Amer, Radzi Shahari, and Tarek Ganat \\ Department of Petroleum Engineering, Universiti Teknologi PETRONAS, P.O. Box 32610 Seri Iskandar, Perak Darul Ridzuan, \\ Kuala Lumpur, Malaysia \\ Correspondence should be addressed to Syahrir Ridha; syahrir.ridha@utp.edu.my
}

Received 27 November 2018; Revised 11 January 2019; Accepted 15 January 2019; Published 26 February 2019

Academic Editor: Donald L. Feke

Copyright (c) 2019 Arif Ibrahim et al. This is an open access article distributed under the Creative Commons Attribution License, which permits unrestricted use, distribution, and reproduction in any medium, provided the original work is properly cited.

Application of carbon nanomaterials in oil well drilling fluid has been previously studied and was found to enhance its filtration properties. There is a general consensus that addition of colloids in suspension will alter its rheology, i.e., carbon nanomaterials, in this research work; graphene nanoplatelets are hydrophobic materials, which require functionalisation to improve its dispersion in aqueous solution. However, different degrees of dispersion may vary the rheological properties behaviour of drilling fluid. The objective of this study was to characterize the colloidal dispersion of graphene nanoplatelets (GNP) in aqueous solution and its impact on the rheological properties behaviour of water-based drilling fluid. Dispersion of graphene nanoplatelets was achieved through noncovalent functionalisation by means of surfactant attachment. UV-visible spectroscopy was employed to analyze the dispersion of GNP in aqueous solution. The rheological test was carried out using a simple direct-indicating viscometer at six different speeds. Results revealed that the degree of dispersion of GNP using Triton X-100 was generally higher than both SDS and DTAB. Comparison between the rheological properties behaviour of drilling fluid with GNP dispersed using different surfactants shows little to no difference at low shear rates. At high shear rates, however, greater dispersion of GNP shows higher thinning properties while fluid with a low dispersion of GNP exhibited linear behaviour to thickening properties.

\section{Introduction}

Oil well drilling fluid or commonly known as drilling muds are a complex colloidal system that is a trivial part for an oil well drilling operation. Apart from its primary function in conventional drilling operation where drilling fluid acts as a safety barrier which prevents formation fluid from flowing into the well, drilling fluid also needs to carry drilled cuttings to the surface. The ability of a fluid to suspend and lift cuttings to the surface is related to its rheological properties. Improper design of rheological properties of drilling fluid may affect its ability to remove cuttings from the wellbore which in turn may cause stuck pipe and damaged bottom hole assembly.

Graphene, the world's first two-dimensional (2D) crystalline material, has a theoretical thickness of $0.34 \mathrm{~nm}$ $[1,2]$ and is composed of a single layer of carbon atoms in the $\mathrm{sp}^{2}$ hybridisation state with each atom covalently bonded to three other carbon atoms in a hexagonal lattice with a carbon-to-carbon distance of $0.142 \mathrm{~nm}[3,4]$. Graphene is the building block of other carbon materials. For example, the sheets can be curved into 0D fullerene, rolled into $1 \mathrm{D}$ carbon nanotubes (CNTs), or stacked into 3D graphite [3]. Although theoretical prediction on the unique electronic structure and the linear dispersion relation of graphene started almost 70 years ago (1947) by P. R. Wallace, the first physical isolation of graphene happened only recently. The discovery is attributed to Andre K. Geim and Konstantin Novoselov, researchers from Manchester University back in 2004, which gave them the honour of being awarded the Nobel Prize for Physics in 2010 [3].

The unique properties of graphene are a direct consequence of its structure. It has been reported that the strength of graphene exceeds $1.5 \mathrm{TPa}$ due to its extremely strong in- 
plane $\sigma$-bonds ( $670 \mathrm{~kJ} / \mathrm{mol}$ ) [4], while the remaining $\pi$-orbits perpendicular to the plane constitute the delocalized network of electrons which makes the structure highly conductive [3]. The thermal conductivity of graphene was reported to be $5000 \mathrm{~W} \mathrm{~m}^{-1} \mathrm{~K}^{-1}$ which is better than many metals [4] again because of the strong $\mathrm{sp}^{2}$ bonds that help dissipate heat via lattice vibration or phonon scattering [3]. In addition, graphene has also been proven to be able to form a membrane impermeable to even the hardest gas to filter, helium $[5,6]$. In recent years, applications of graphene and its predecessor, CNTs, have been getting a lot of attention for research in oil and gas industry especially drilling fluids and were proven to have improved the conventional drilling fluid system [7-9].

A key requirement for carbon research and applications is the ability to identify and characterize all the members of the carbon family. Over the years, several literature studies have characterised carbon allotropes using Raman spectroscopy due to its fast, nondestructive, and high resolution with maximum structural and electronic information [1018]. In addition, Raman spectroscopy is highly sensitive to symmetric covalent bonds with little to no natural dipole moment [19].

The main features of carbon allotropes in Raman spectra are the so-called $G$ and $G^{\prime}$ peaks, which lie at around $\sim 1580 \mathrm{~cm}^{-1}$ and $\sim 2700 \mathrm{~cm}^{-1}$, respectively. Graphene can be distinguished from graphite by thoroughly examining the $G^{\prime}$ peak of the Raman spectra as studied by Ferrari et al. [20]. Single graphene has a single $G^{\prime}$ peak roughly four times more intense than its $G$ peak, while bilayer graphene's $G^{\prime}$ peak consists of four components and bulk graphite's $G^{\prime}$ peak consists of two components roughly $1 / 4$ and $1 / 2$ the height of the $G$ peak. This result is in agreement with Gupta et al. [21] and Dresselhaus et al. [22]. Gupta et al. [21] and Dresselhaus et al. [22] found that single-layer graphene exhibits sharp $G$ and $G^{\prime}$ peak at $\sim 1580 \mathrm{~cm}^{-1}$ and $\sim 2700 \mathrm{~cm}^{-1}$, respectively while multilayer graphene or graphite exhibit broad $G^{\prime}$ peaks which can differentiate the number of carbon layers.

In addition, Dresselhaus et al. [22] differentiated the Raman spectra between graphene, graphite, and carbon nanotubes. While a single $G$ peak is observed for a $2 \mathrm{D}$ graphene sheet, curvature effect such as in carbon nanotubes gives rise to multiple $G$ peaks. Another significant difference is the existence of the radial breathing mode (RBM) in Raman spectra of carbon nanotubes which is in the range of $\sim 120 \mathrm{~cm}^{-1}$ to $350 \mathrm{~cm}^{-1}$ that is related to the diameter of the carbon nanotubes. Graf et al. [23] also used Raman spectroscopy to differentiate graphite flakes of different thicknesses at 532 excitation wavelengths. Although Graf et al. [23] used different excitation wavelengths, the results are conclusively similar to Ferrari et al. [20], Gupta et al. [21], and Dresselhaus et al. [22].

Raman signature and the specific peak position of any material is related to the material's unique structure and is independent of the excitation wavelength, so the molecular fingerprint will be the same regardless of the excitation laser wavelength. However, different excitation wavelengths provide specific strengths and weaknesses and may impose 'noise' in the resulting spectra. Ferrari et al. [20] compares the $G^{\prime}$ peak of graphene and graphite measured at two different excitation wavelengths. Although the shape of the spectra remains the same even at similar shift, its efficiency and resolution drops quite significantly at $633 \mathrm{~nm}$ as compared to $514 \mathrm{~nm}$. Luo et al. [24], in addition, studied the Raman spectra of hydrogenated graphene at five different excitation wavelengths: $457 \mathrm{~nm}, 488 \mathrm{~nm}, 532 \mathrm{~nm}, 633 \mathrm{~nm}$, and $785 \mathrm{~nm}$. Among the five different laser-excitation wavelengths, results show that excitation wavelength of $532 \mathrm{~nm}$ produces the best Raman spectra with minimal noise for hydrogenated graphene.

Calculation of the number of layers of graphene is possible from the position of the $G$ band. As explained by Wall et al. [25], the theory is that as the layer thickness increases, the band position shifts to lower energy, representing a slight softening of the bonds. Thus, the band position can be empirically correlated to the number of atomic layers present using the following equation [25]:

$$
\omega_{G}=1581+11\left(1+n^{1.6}\right),
$$

where $\omega_{G}$ is the position of $G$ peak in wavenumbers and $n$ is the number of layers present in the sample.

Despite all the great properties of graphene, individual graphene approaching each other may establish $\pi-\pi$ bond like in graphite. This interaction may sum up and bundle graphene together which makes dispersing it in aqueous solution difficult. Functionalising graphene is essential as it allows graphene to be dispersed in solutions, to graft desired functions on their surface or to be coupled with other materials [26].

Generally, there are two methods to functionalise graphene to achieve dispersion in aqueous solutions: covalent functionalisation and noncovalent functionalisation $[4,20,27]$. The covalent functionalisation method involves attaching various chemical moieties to improve its solubility in solvents. This method, however, can be considered aggressive as it occurs at high temperature and includes the use of dangerous chemicals such as the use of neat acids [28]. In addition, as a result of attaching different functional groups, the structure of graphene is altered, consequently changing the properties of graphene as well. Noncovalent functionalisation, on the other hand, is particularly attractive because of the possibility of attaching various groups on the surface of graphene without disturbing its structure and properties [26].

Surface-active agents or widely known as surfactants have been extensively used to disperse carbon nanomaterials via the noncovalent method. The structure of surfactants consists of two parts, one of which is a hydrophobic tail, usually a hydrocarbon chain, and the other is a polar hydrophilic head which may be cationic, anionic, or nonionic in nature [29]. Surfactants help achieve homogenous dispersion of carbon nanomaterial in aqueous solutions by wrapping it or forming micelle around each individual nanomaterial [28]. To date, a wide variety of surfactants and concentrations have been investigated to disperse carbon nanomaterials in aqueous solution such as sodium dodecyl benzene sulfonate (SDBS) [30], dodecyl trimethyl ammonium bromide (DTAB) [10], hexadecyl trimethyl ammonium bromide (CTAB) [11], octyl phenol ethoxylate (Triton 
$\mathrm{X}-100)$ [12, 13], and sodium dodecyl sulfate (SDS) $[7,9,19,22,25,26]$.

Our previous research work shared results on the filtration properties of water-based drilling fluid with the inclusion of graphene nanoplatelets without the emphasis on the degree of dispersion [31]. In addition, Aftab et al. [7] also studied the usage of graphene nanoplatelets in water-based drilling fluid including filtration, rheology, and shale inhibition. Functionalisation of graphene nanoplatelets was achieved through noncovalent functionalisation using sodium dodecyl sulfate (SDS), an anionic surfactant. However, effect of factors such as degree of dispersion was not reported. In 2011, Pu et al.'s [32] research found that homogeneity of graphene dispersion in aqueous media differs with different types of surfactants. Thus, the research question is will the effect of different degrees of dispersion of graphene affect the ability of graphene as an additive for drilling fluid application or more specifically of this study, rheology.

In this work, the dispersion of graphene nanoplatelets in aqueous solutions using three different types of surfactants was studied: SDS, DTAB, and Triton X-100. Graphene nanoplatelets were dispersed in aqueous solutions of different concentrations of surfactants by means of ultrasonic bath at $30^{\circ} \mathrm{C}\left(86^{\circ} \mathrm{F}\right)$. Colloidal dispersion of graphene nanoplatelets in aqueous surfactant solutions was studied by means of UV-Vis spectroscopy. The impact of different degrees of dispersion on rheological properties behaviour of water-based drilling fluid was then studied using a simple direct-indicating Fann viscometer.

\section{Materials and Methods}

2.1. Materials. Graphene nanoplatelets with a diameter of $40-70 \mathrm{~nm}$, length of $2-5 \mathrm{~nm}$, and purity of $>95 \mathrm{wt} . \%$ were procured from Sigma-Aldrich. The usage of SDS (98\% purity from Aldrich) along with two other surfactants of different types, namely, DTAB (99\% purity from Aldrich), a cationic surfactant, and Triton X-100 (97\% purity from Aldrich), was employed to disperse graphene nanoplatelets in the waterbased drilling fluid, a nonionic surfactant. Figure 1 shows the chemical structure of (a) DTAB, (b) SDS, and (c) Triton $\mathrm{X}-100$. The selection of these surfactants is based on the representative used in literature for nonionic- and ionicbased surfactants. As its name suggests, DTAB is composed of a hydrophobic carbon tail attached to an ammonium head with three methyl groups. SDS, on the other hand, is composed of a hydrophobic carbon tail attached to a sulfate group, while Triton X-100 is composed of a hydrophilic polyethylene oxide chain and an aromatic hydrocarbon hydrophobic group.

2.2. Graphene Nanoplatelets Characterisation. Graphene nanoplatelets characterisation methods employed in this research work include Raman spectroscopy, FESEM, and TEM. Raman spectroscopy provides high-resolution structural and electronic information while the field emission scanning electron microscopy (FESEM) and high-resolution transmission electron microscopy (HRTEM) provide microscopic imaging for visual purposes. Raman spectroscopy is a spectroscopic technique used to observe vibrational, rotational, and other low-frequency modes in a system. In this research work, the structural fingerprint of graphene nanoplatelets was analysed at $514 \mathrm{~nm}$ laser excitation wavelength using Horiba JobinYvon HR800 in Centralized Analytical Laboratory (CAL) in Universiti Teknologi PETRONAS (UTP). FESEM was carried out using a variable pressure field emission scanning electron microscope (VP-FESEM) Zeiss Supra55 in Centralized Analytical Laboratory (CAL) in Universiti Teknologi PETRONAS (UTP). Uncoated powder samples of the materials were mounted on a grid holder and were spincoated with gold to enhance electron conductivity. An accelerating voltage of $5 \mathrm{kV}$ was used to view the nanomaterials. HRTEM was carried out using FEI, TECNAIG2-20-200kV-S-TWIN High-Resolution Transmission Electron Microscope (HRTEM) at Science and Engineering Research Centre (SERC) in Universiti Sains Malaysia (USM). A small amount of sample was dispersed using a solvent in a test tube and was ultrasonicated for one hour. The samples were then left standing for another 30 minutes before dropping on a copper grid. The sample was then left to dry overnight prior to HRTEM analysis.

\subsection{Preparation of Dispersion of Graphene Nanoplatelets in} Surfactant Solutions. All surfactant solutions were prepared by mixing the calculated amount of each surfactant in $50 \mathrm{~mL}$ of distilled water in an Erlenmeyer flask. Five concentrations were prepared for each surfactant to properly reflect the effect of various concentrations on dispersion stability: $100 \mathrm{ppm}$, $200 \mathrm{ppm}, 300 \mathrm{ppm}, 400 \mathrm{ppm}$, and $500 \mathrm{ppm}$ resulting in 15 total solutions. A fixed amount of $1 \mathrm{mg}$ of graphene nanoplatelets per $1 \mathrm{~mL}$ of surfactant solutions was then dispersed in all solutions. The resultant solutions were then ultrasonicated at $100 \mathrm{kHz}$ for 30 minutes at $30^{\circ} \mathrm{C}\left(86^{\circ} \mathrm{F}\right)$ in an ultrasonic bath in order to get surfactant-coated graphene.

2.4. Colloidal Dispersion Analysis. To evaluate colloidal dispersion of graphene nanoplatelets in the aqueous surfactant solution, UV-Vis absorption spectra between $200 \mathrm{~nm}$ and $700 \mathrm{~nm}$ were measured (PerkinElmer UV/Vis Spectrometer Lambda 25) with $1.00 \mathrm{~nm}$ slit width. Yu et al. [16] in their literature discovered that individual carbon nanotubes (CNTs) are active in the UV-Vis region and exhibit corresponding characteristics band with additional CNTs in suspension due to $1 \mathrm{D}$ van Hove singularities [33]. In addition, flocculated CNTs are inactive in the wavelength region between 200 and $1200 \mathrm{~nm}$. Thus, it is possible to establish a relationship between the amount of dispersion stability of CNTs and the intensity of the corresponding absorption spectrum [34]. Similar with CNTs, the dispersion of graphene can also be evaluated by UV-Vis spectroscopy. For all surfactant solution with graphene nanoplatelets, respective surfactant solution without graphene nanoplatelets was used as a calibration reference. 


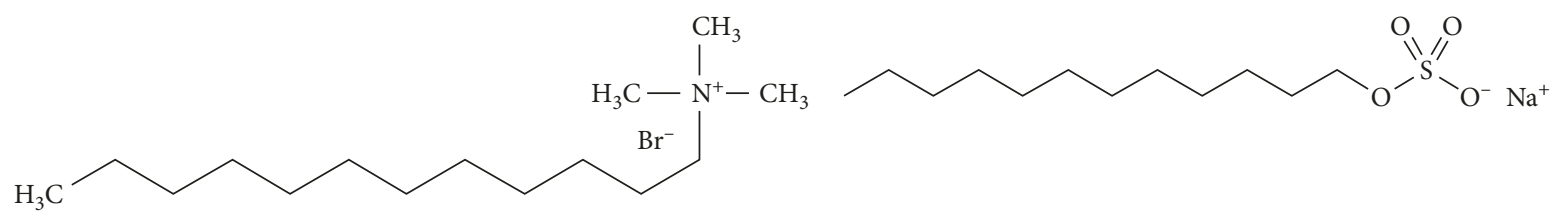

(a)

(b)

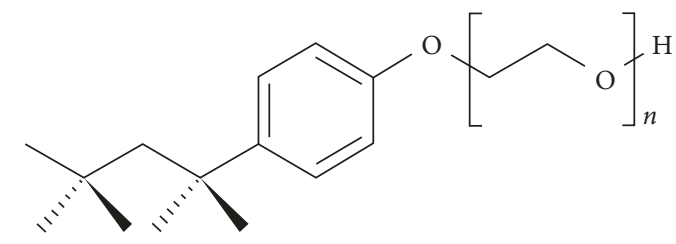

(c)

Figure 1: Chemical structure of (a) DTAB, (b), SDS, and (c) Triton X-100.

2.5. Drilling Fluid Formulations and Preparations. $350 \mathrm{~mL}$ of water-based drilling fluid was prepared by mixing distilled water, potassium chloride, xanthan gum, polyanionic cellulose, caustic soda, barite, and graphene nanoplatelets which were dispersed at a fixed concentration of $1 \mathrm{mg} /$ $1 \mathrm{~mL}$ in surfactant solutions. All drilling fluid formulations were formulated with a fixed concentration of $0.1 \mathrm{~g} /$ $350 \mathrm{~mL}$ of graphene nanoplatelets. Table 1 shows the approximate drilling fluid formulations and mixing procedure.

2.6. Rheological Test. Rheological properties behaviour of the drilling fluid was measured following API RP13B-1recommended practice for field-testing water-based drilling fluids [35]. Tests were conducted using Fann VG viscometer, model 35, FANN ${ }^{\circledR}$ Instrument Company (Houston, Texas) at $86^{\circ} \mathrm{F}\left(30^{\circ} \mathrm{C}\right)$. Six dynamics readings were recorded for each run of every formulation; $600 \mathrm{rpm}, 300 \mathrm{rpm}, 200 \mathrm{rpm}$, $100 \mathrm{rpm}, 6 \mathrm{rpm}$, and $3 \mathrm{rpm}$.

While most works of literature described drilling fluid rheological properties by simply explaining the plastic viscosity and yield point, Sharma et al. [36] suggest fluids which contain nanomaterials that mostly exhibit nonlinear behaviour. At this profile, the Bingham plastic model may not be the most suitable mathematical model in explaining the rheological properties behaviour of fluids with multiple colloid suspensions especially with the inclusion of nanomaterials. A more accurate method would be to plot a rheogram with a shear rate and shear stress as was used by Ho et al. [37] and Srivatsa et al. [38] despite the fact that Ho et al. [37] used a more advanced rheometer instead of FANN ${ }^{\circledR}$ viscometer. Although some calculations are needed, the rheogram of shear stress vs shear rate can be plotted by converting the $\mathrm{FANN}^{\circledR}$ viscometer reading into shear stress and shear rate as explained by Lam and Jefferis [39]. Rheological properties behaviour can then be explained by interpreting the curve in the rheogram.

The shear viscosity of a fluid at a given shear rate is given as follows:

$$
\mu=\frac{\tau}{\gamma}
$$

TABLE 1: Drilling fluid formulations and mixing procedure.

\begin{tabular}{lccc}
\hline Functional materials & $\begin{array}{c}\text { Concentrations } \\
(\mathrm{g})\end{array}$ & $\begin{array}{c}\text { Mixing time } \\
(\mathrm{min})\end{array}$ & $\begin{array}{c}\text { Mixing } \\
\text { order }\end{array}$ \\
\hline Distilled water & 200.0 & - & 1 \\
Potassium chloride & 20.0 & 2 & 2 \\
Xanthan gum & 1.0 & 5 & 3 \\
Polyanionic cellulose & 3.0 & 5 & 4 \\
Caustic soda & 0.1 & 5 & 5 \\
Barite & 160.0 & 30 & 6 \\
Graphene & 0.1 & 15 & 7 \\
nanoplatelets & 100 & 15 & 7 \\
Surfactant solutions & & &
\end{tabular}

where $\mu=$ viscosity in $\mathrm{mPa} \cdot \mathrm{s}, \tau=$ shear stress at the given shear rate in $\mathrm{Pa}$, and $\gamma=$ shear rate in $\mathrm{s}^{-1}$.

Based on the design of $\mathrm{FANN}^{\circledR}$ Instrument 35SA viscometer, viscosity can be calculated using the following equation in the unit of $\mathrm{mPa} \cdot \mathrm{s}$ :

$$
\mu=k \times f \times \frac{\theta}{\omega}
$$

where $\mu=$ viscosity in $\mathrm{mPa} . \mathrm{s}, k=300$ for the standard rotorbob combination, $f=1$ for the standard torsion spring $\mathrm{F} 1$, $\theta=$ dial reading, and $\omega=$ rotor speed in $\mathrm{rpm}$.

Equation (3) then becomes

$$
\mu=300 \times 1 \times \frac{\theta}{\omega} .
$$

Solving Equations (3) and (4) for shear stress and unit conversion results in the following equation to get shear stress as a function of shear rate and viscosity, we obtain

$$
\tau=\frac{\gamma \times \mu}{1000} .
$$

\section{Results and Discussion}

3.1. Graphene Nanoplatelets Characterisation. Figure 2 presents the Raman spectra of the procured graphene nanoplatelets between $200 \mathrm{~cm}^{-1}$ and $3200 \mathrm{~cm}^{-1}$ with a laser excitation wavelength of $514 \mathrm{~nm}$. The $G$ and $G^{\prime}$ of the graphene nanoplatelets are located at $1582.36 \mathrm{~cm}^{-1}$ and $2731.66 \mathrm{~cm}^{-1}$, respectively. It can be observed that no peak 


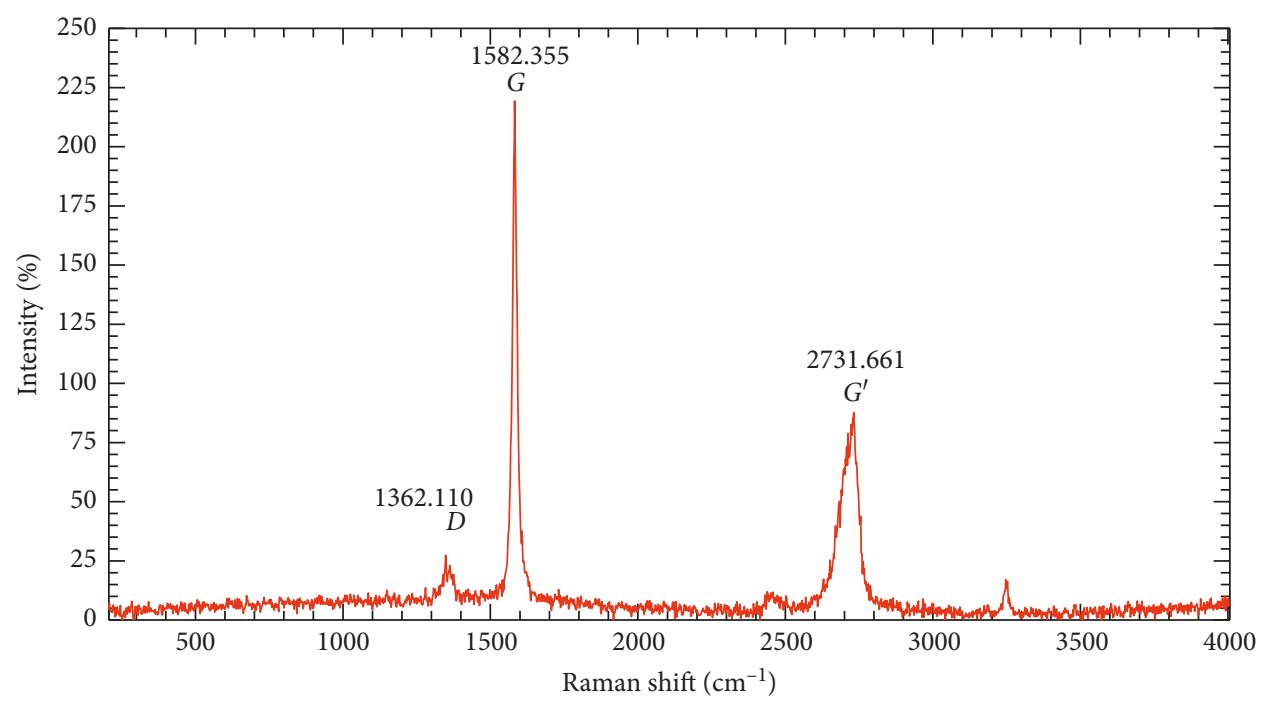

FIGURE 2: Raman spectroscopy of graphene nanoplatelets at $514 \mathrm{~nm}$ excitation wavelength.

exists in the range between $200 \mathrm{~cm}^{-1}$ and $350 \mathrm{~cm}^{-1}$ which meant there are no curvature in the sample edges like in carbon nanotubes. Based on the ratio of the height of the $G$ and $G^{\prime}$ peaks which is around 2.9, it shows that the procured graphene nanoplatelets structure resembles more of a highly oriented pyrolytic graphite as compared to pristine graphene. This is due to the existence of multiple layers of carbon atoms in the samples. Using Equation (1), the number of layers can be calculated and was found to be five layers. The number of layers of the graphene nanoplatelets was then confirmed using HRTEM.

Figure 3 shows morphology of graphene nanoplatelets as viewed using FESEM at $1 \mathrm{k}, 10 \mathrm{k}, 80 \mathrm{k}$, and $100 \mathrm{k}$ times magnifications. At $1 \mathrm{k}$ times magnification, it can be seen that the edges of graphene nanoplatelets sheets folded in ambient air conditions creating irregular bundles of graphene nanoplatelets. At higher magnification, FESEM images could further characterize the shape of graphene nanoplatelets. It can be seen that the morphology of graphene nanoplatelets is that of flaky graphene sheets with an average of $20 \mathrm{~nm}$ in thickness. Figure 4 on the other hand shows an image of graphene nanoplatelets edge observed by using HRTEM at 1,000k times magnifications. It can be observed that the thickness of the graphene nanoplatelets is $1.869 \mathrm{~nm}$ average with a distance between graphene layers of $0.405 \mathrm{~nm}$ average making the number of layers 5 . Results of the number of layers of graphene sheets from HRTEM are in agreement with analysis acquired by Raman spectrometry.

3.2. Colloidal Dispersion. The absorption spectra of graphene nanoplatelets in DTAB, SDS, and Triton X-100 are illustrated in Figures 5-7, respectively. Pure DTAB and SDS show no absorption at $250-300 \mathrm{~nm}$ in UV-Vis spectra. These surfactants contain hydrophilic functional groups $-\mathrm{SO}_{4}{ }^{-}$for SDS and $-\mathrm{CH}_{3}{ }^{-}$for DTAB on the outer end of the long chain which adsorbs on graphene. Note that unlike other surfactants, Triton X-100 without graphene shown in
Figure 7(f) exhibits multiple peaks most noticeably around $280 \mathrm{~nm}$. This attribute is due to the existence of the aromatic hydrocarbon lipophilic group in its structure. Similar peak pattern was also observed in other nonionic surfactant solutions [32].

The absorption spectra of DTAB (Figure 5) and SDS (Figure 6) show the similar trend; the dispersion of graphene nanoplatelets in water increases with increasing surfactant concentration with the exception of $400 \mathrm{ppm}$ and $500 \mathrm{ppm}$ of SDS which exhibited equal absorption values. The similar values may suggest two different views: the optimum concentration of SDS to help disperse graphene nanoplatelet in water is $400 \mathrm{ppm}$ or there is not enough graphene nanoplatelets to be dispersed in $500 \mathrm{ppm}$ SDS solution. The second opinion, however, is less attractive due to the fact that the absorption spectra of graphene nanoplatelets in Triton X-100 (Figure 7) exhibited more than twice the value of SDS. The absorption trend of graphene nanoplatelets with Triton X-100 (Figure 4) displays a rather different trend than the other two surfactants. The $100 \mathrm{ppm}$ surfactant concentration of Triton $\mathrm{X}-100$ shows the best dispersion stability followed by $200 \mathrm{ppm}$, while increasing from $300 \mathrm{ppm}$ to $500 \mathrm{ppm}$ indicates little to no difference in dispersion stability. This phenomenon might be due to reaggregation of graphene nanoplatelets due to the excessive surfactant used which was also observed by other nonionic surfactant solutions [32].

Comparing the UV-Vis spectra of all three surfactants used with similar concentrations, it was found that the nonionic type of surfactant performed well at dispersing graphene nanoplatelets in water. This result can be attributed to the lower critical micellization concentration point of nonionic surfactants as compared to ionic surfactants [40]. The difference in dispersion capability between surfactants can also be explained on the basis of their chemical structure. Surfactants contribute in achieving homogenous dispersion of graphene nanoplatelets in aqueous solutions by wrapping it or forming a micelle around each individual graphene. In 


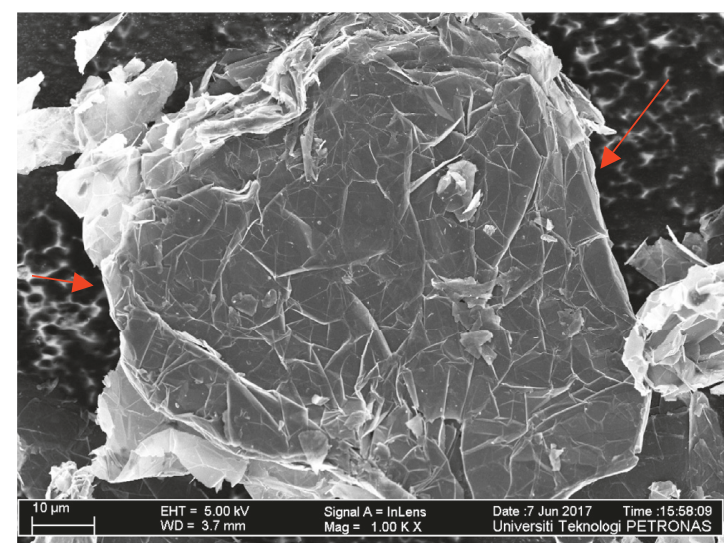

(a)

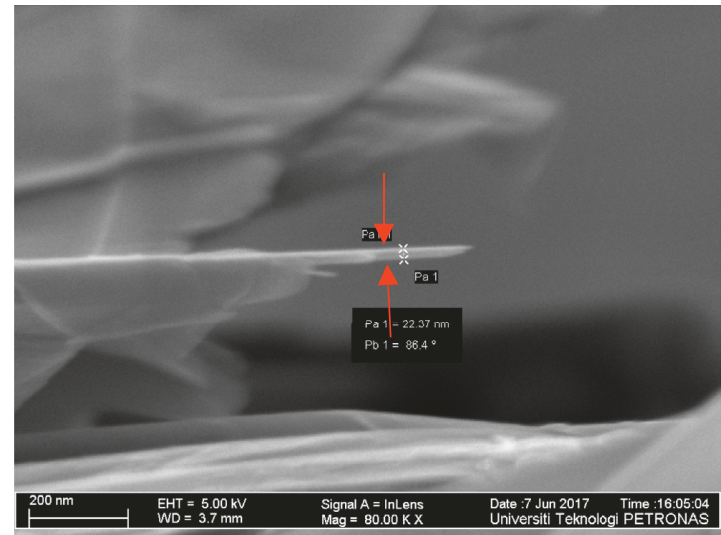

(c)

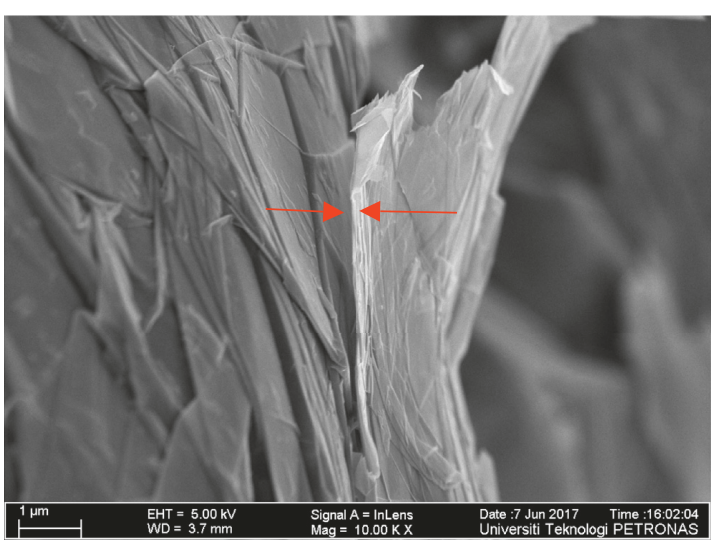

(b)

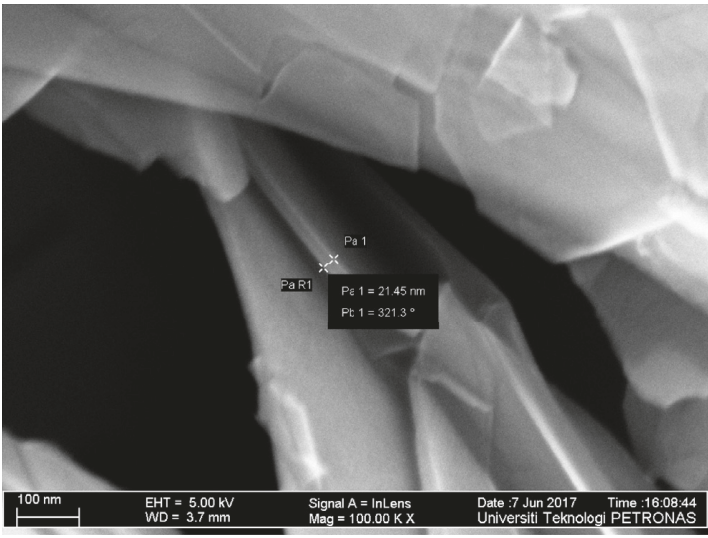

(d)

FIGURE 3: Morphology of graphene nanoplatelets as seen under FESEM.

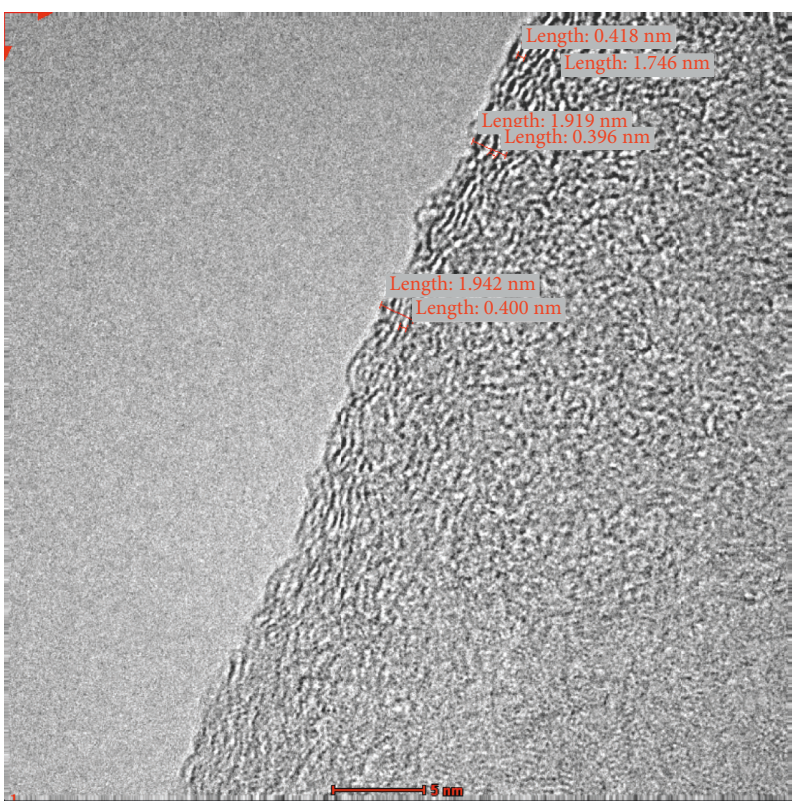

FIGURE 4: HRTEM image of graphene nanoplatelets viewed at 1,000,000 magnification.

order to do so, the surfactants orient itself so that the hydrophobic tail is directed towards the graphene while their hydrophilic head is directed towards the aqueous solutions
[28]. Therefore, the dispersing power of the surfactant depends on the length of the hydrophobic tail and how firmly it adsorbs onto the graphene surface and produces energy 


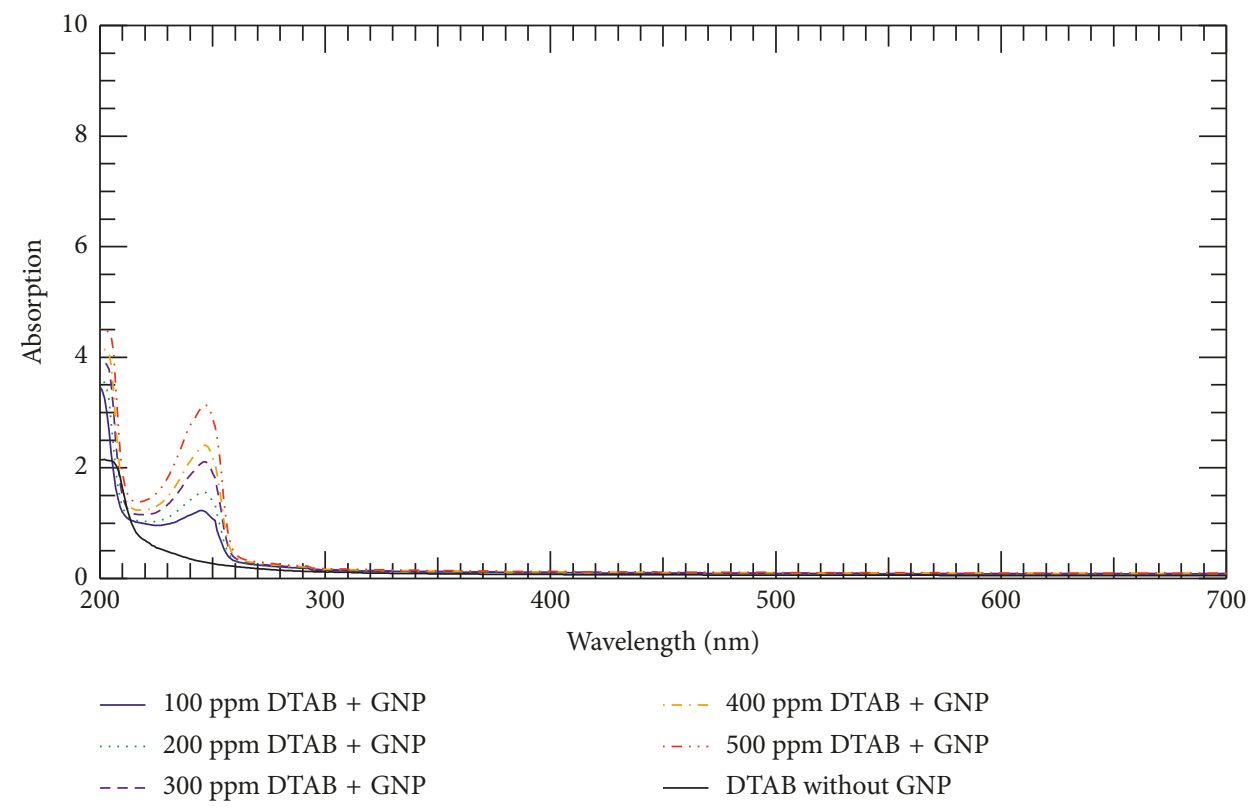

FIGURE 5: UV-Vis spectra of graphene nanoplatelets in DTAB solutions after 30-minute ultrasonication.

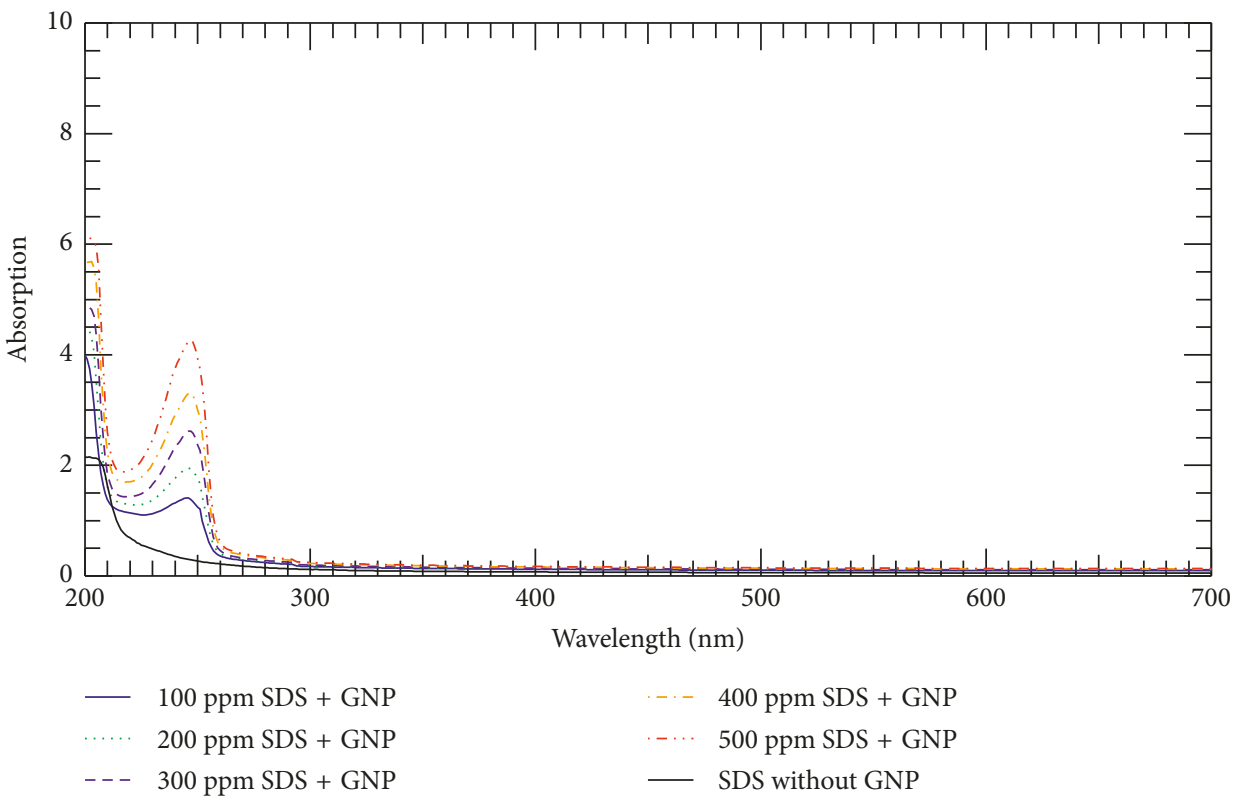

FIGURE 6: UV-Vis spectra of graphene nanoplatelets in SDS solutions after 30-minute ultrasonication.

barriers of sufficient height to overcome Van der Waals forces among the neighboring graphene particles. Thus, longer tails mean higher steric hindrance, providing greater repulsive forces between individual graphene as can be seen with the difference in structure and performance of DTAB and SDS. In addition, theoretically, molecules with aromatic ring structure have stronger adsorption ability to the graphitic surface due to $\pi-\pi$ stacking-type interaction [30]. This explains why the nonionic surfactant Triton X-100 with aromatic rings produces a higher degree of colloidal dispersion.

3.3. Rheological Behaviour. Rheological properties behaviour of water-based drilling fluid with $0.1 \mathrm{~g}$ of graphene nanoplatelets dispersed using DTAB, SDS, and Triton $\mathrm{X}-100$ is illustrated in Figures $8-10$. From the rheogram, it can be seen that, at a low shear rate, the rheological properties behaviour of the drilling fluid does not seem to be affected by the degree of dispersion of graphene nanoplatelets for all three surfactants. At high shear rates, however, the degree of dispersion of graphene nanoplatelets does have an impact on the rheological properties behaviour of the drilling fluid. This is evident by observing the difference of shear stress between all three surfactants at $1022 \mathrm{~s}^{-1}$. The $100 \mathrm{ppm}$ of Triton X-100 which exhibited the highest degree of dispersion have a lower shear stress value at $1022 \mathrm{~s}^{-1}$ shear rate as compared to two other surfactant solutions. This, in turn, provides greater shear-thinning 


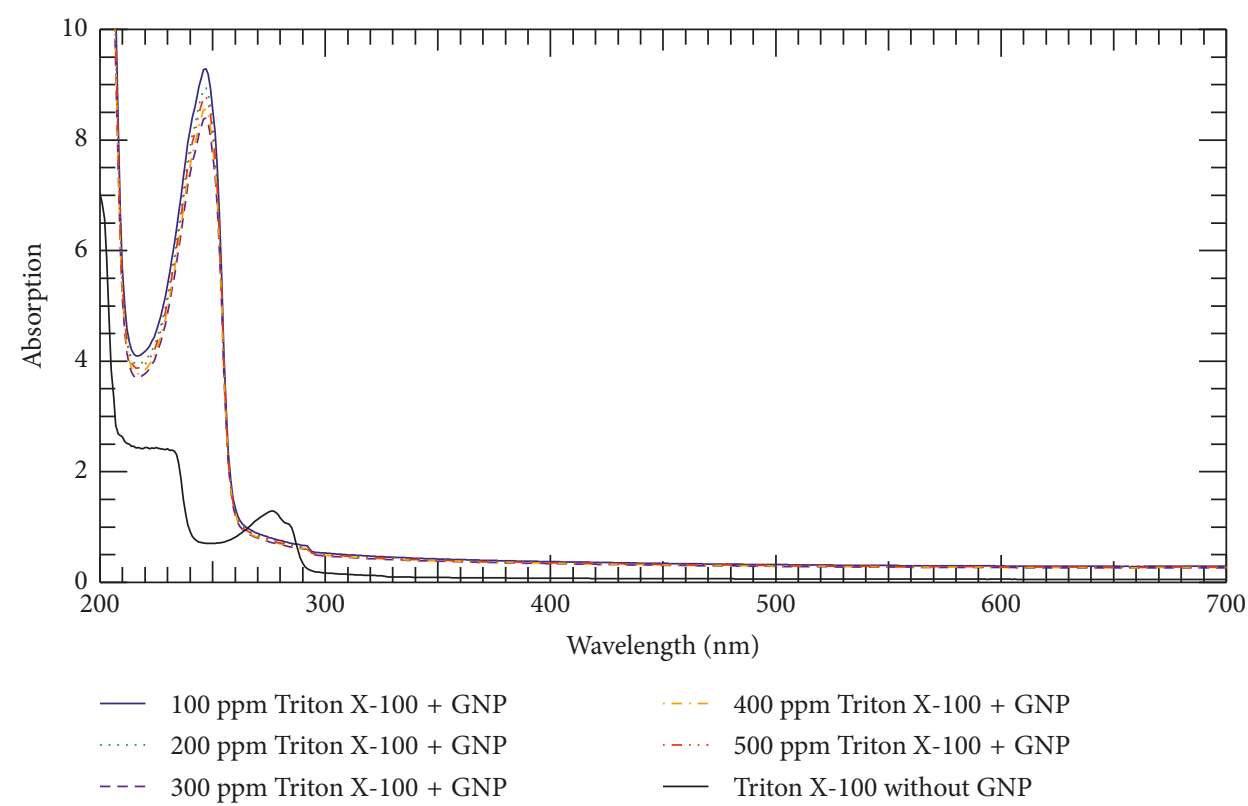

Figure 7: UV-Vis spectra of graphene nanoplatelets in Triton X-100 solutions after 30-minute ultrasonication.

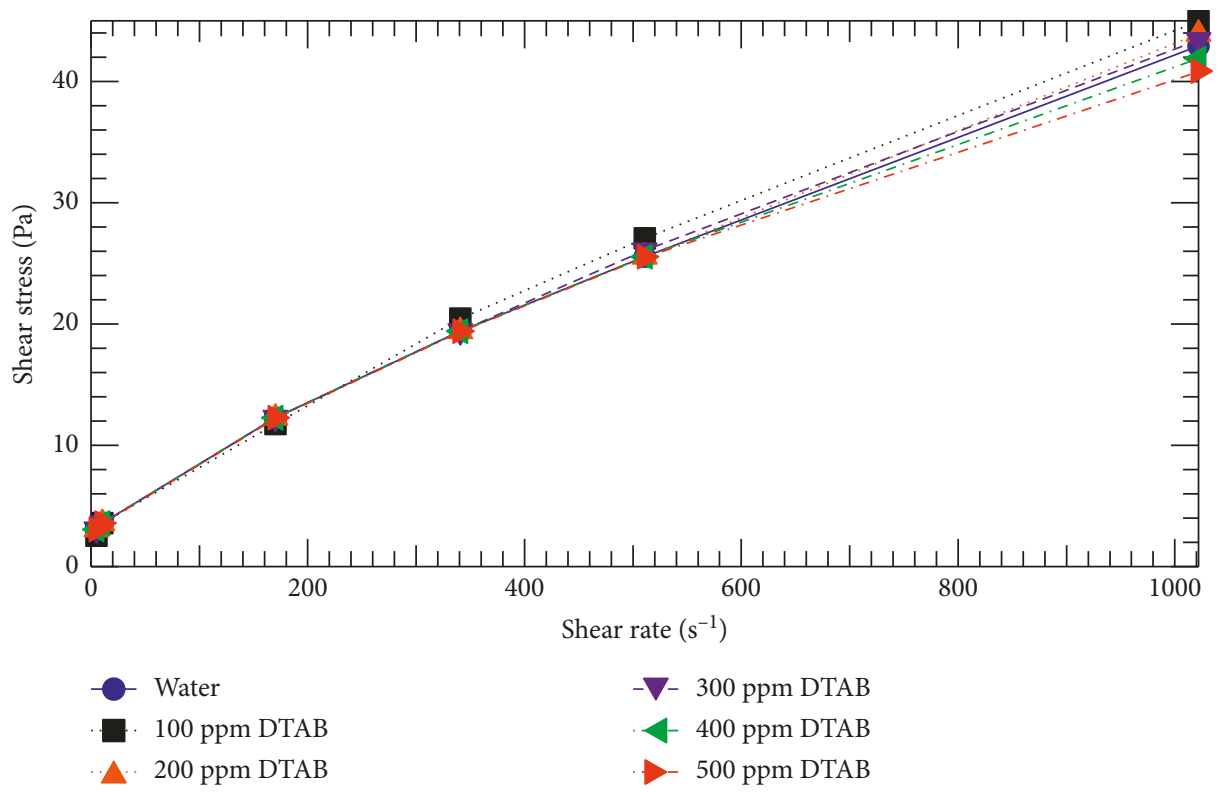

FIGURE 8: Rheogram of water-based drilling fluid with $0.1 \mathrm{ppb}$ of graphene nanoplatelets dispersed using DTAB.

properties of the drilling fluid which is a more desirable behaviour in a drilling fluid.

It can also be observed that, at a lower degree of dispersion such as with $100 \mathrm{ppm}$ of SDS and $100 \mathrm{ppm}$ of $\mathrm{DTAB}$, the rheological properties behaviour at a high shear rate is almost linear and is higher than the fluid sample with graphene nanoplatelets dispersed in water. This might be due to agglomerations of graphene nanoplatelets as suggested by Chai et al. [37] although used a different type of base fluid or due to the properties of surfactants used.

It can also be argued that the change in rheological properties behaviour is due to the addition of surfactants used to disperse graphene nanoplatelets in drilling fluid. However, Yunita et al. [41, 42] investigated the use of nonionic- and anionic-type surfactants in the water-based drilling fluid and found that drilling fluid exhibited higher viscosity with the introduction of surfactants in the mix. Meanwhile, in this research work, with the introduction of graphene nanoplatelets and surfactants in the mix, drilling fluid formulated using graphene nanoplatelets with anionic and cationic surfactants exhibited a higher viscosity at a lower concentration which may be due to the surfactants used or can also mean a lower degree of dispersion. Drilling fluid formulated using graphene nanoplatelets with the nonionic surfactant in this research exhibited a lower 


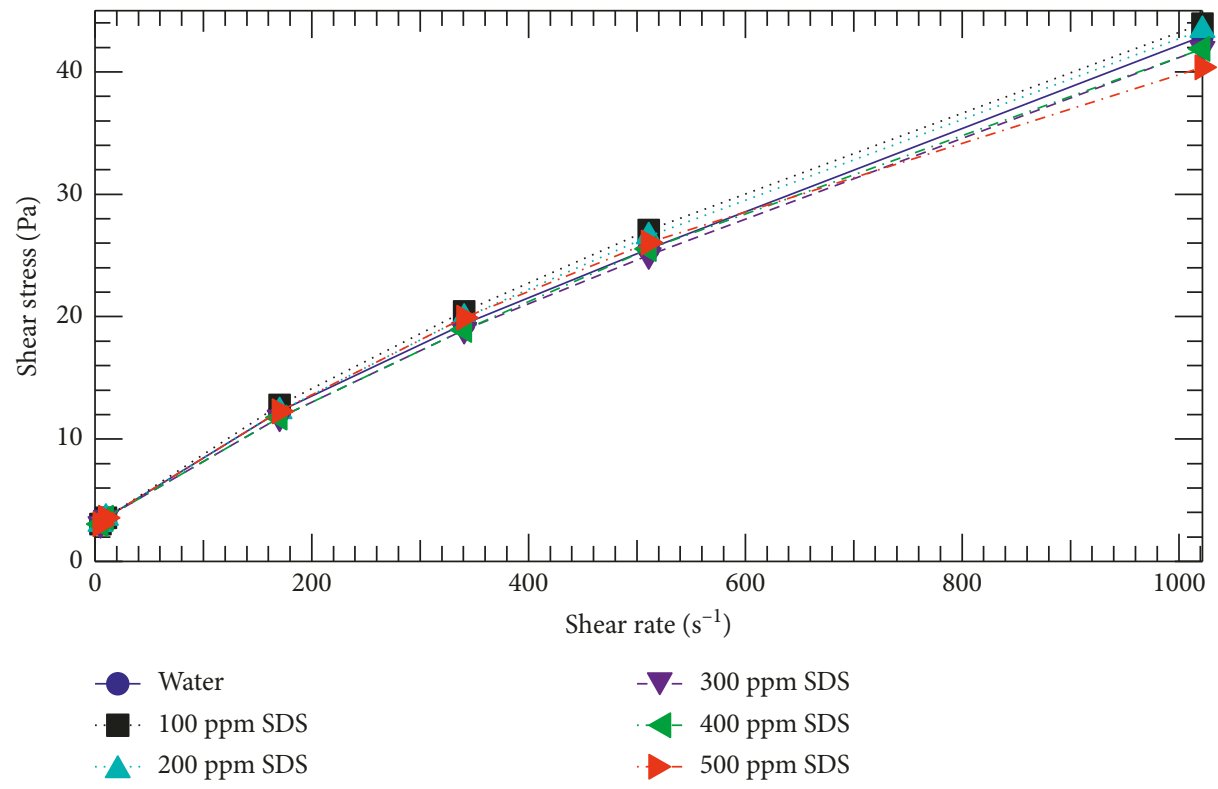

FIGURE 9: Rheogram of water-based drilling fluid with $0.1 \mathrm{ppb}$ of graphene nanoplatelets dispersed using SDS.

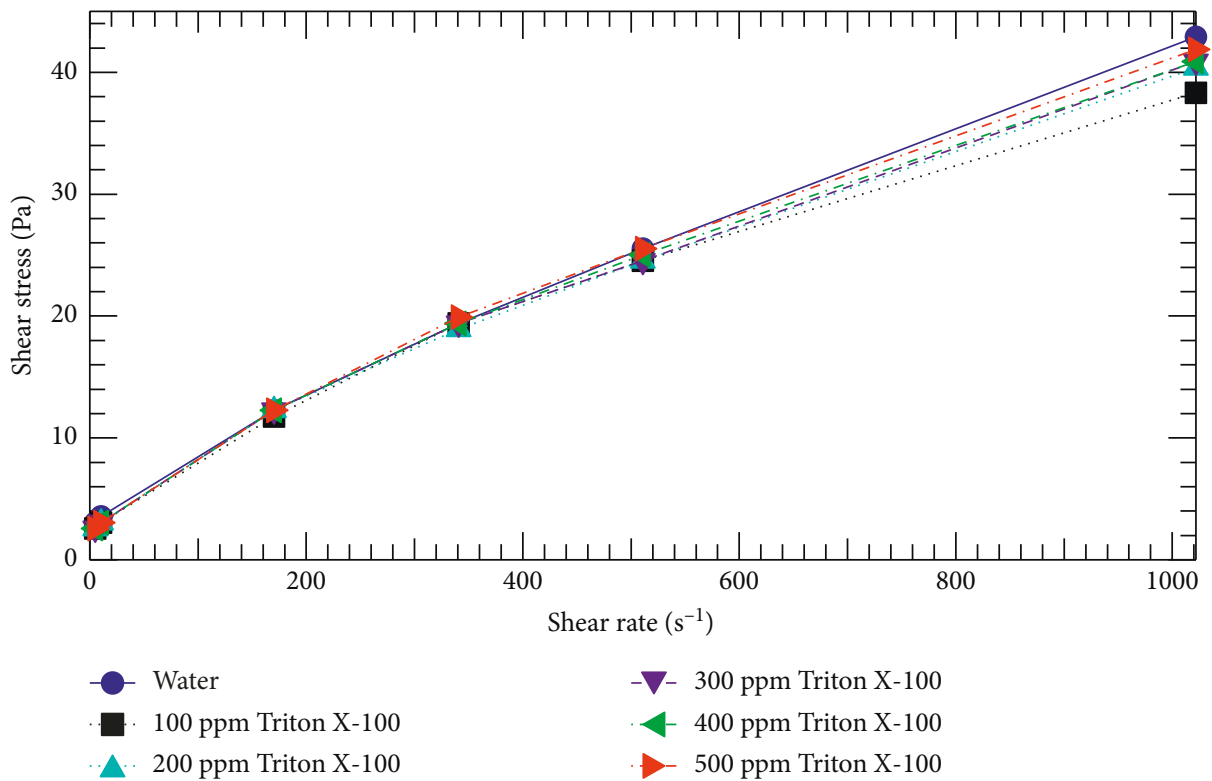

FIgURE 10: Rheogram of water-based drilling fluid with $0.1 \mathrm{ppb}$ of graphene nanoplatelets dispersed using Triton X-100.

viscosity at every concentration. This concludes that the lower viscosity of the drilling fluid is due to the introduction of graphene nanoplatelets and that the surfactants used have minimal effect on the rheological properties behaviour as compared to graphene nanoplatelets.

\section{Conclusions}

The colloidal dispersion of graphene nanoplatelets was achieved through noncovalent functionalisation by encapsulating the graphene with micelles of the surfactant by means of $\pi-\pi$ bond stacking. Among three surfactants used in this research work, Triton X-100, a nonionic surfactant, produces the best dispersion stability followed by SDS, an anionic-type surfactant, and DTAB, a cationic-type surfactant. Based on the work carried out in this research, it can be concluded that the degree of dispersion of graphene nanoplatelets plays a role in the rheological properties behaviour of the water-based drilling fluid. With a greater degree of dispersion, drilling fluid exhibited higher shearthinning properties while drilling fluid with agglomerated graphene nanoplatelets shows more linear properties if not shear thickening.

\section{Data Availability}

The data used to support the findings of this study are available from the corresponding author upon request. 


\section{Conflicts of Interest}

The authors declare that they have no conflicts of interest.

\section{Acknowledgments}

The authors would like to express their gratitude to Universiti Teknologi Petronas for excellent laboratory facilities and providing financial assistance to this project under grant no. 0153AB-M57.

\section{References}

[1] A. K. Geim and K. S. Novoselov, "The rise of graphene," Nature Materials, vol. 6, no. 3, pp. 183-191, 2007.

[2] A. H. Castro Neto, F. Guinea, N. M. R. Peres, K. S. Novoselov, and A. K. Geim, "The electronic properties of graphene," Reviews of Modern Physics, vol. 81, no. 1, pp. 109-162, 2009.

[3] Y. Gogotsi and V. Presser, Carbon Nanomaterials, CRC Press, Boca Raton, FL, USA, 2013.

[4] K. Tanaka and S. Iijima, Carbon Nanotubes and Graphene, Newnes, Oxford, UK, 2014.

[5] K. T. He, J. D. Wood, G. P. Doidge, E. Pop, and J. W. Lyding, "Scanning tunneling microscopy study and nanomanipulation of graphene-coated water on mica," Nano Letters, vol. 12, no. 6, pp. 2665-2672, 2012.

[6] D. V. Kosynkin, G. Ceriotti, K. C. Wilson et al., "Graphene oxide as a high-performance fluid-loss-control additive in water-based drilling fluids," ACS Applied Materials \& Interfaces, vol. 4, no. 1, pp. 222-227, 2011.

[7] A. Aftab, A. R. Ismail, and Z. H. Ibupoto, "Enhancing the rheological properties and shale inhibition behavior of waterbased mud using nanosilica, multi-walled carbon nanotube, and graphene nanoplatelet," Egyptian Journal of Petroleum, vol. 26, no. 2, pp. 291-299, 2017.

[8] M. I. Abduo, A. S. Dahab, H. Abuseda, A. M. AbdulAziz, and M. S. Elhossieny, "Comparative study of using water-based mud containing multiwall carbon nanotubes versus oil-based mud in HPHT fields," Egyptian Journal of Petroleum, vol. 25, no. 4, pp. 459-464, 2016.

[9] A. R. Ismail, A. Aftab, Z. H. Ibupoto, and N. Zolkifile, "The novel approach for the enhancement of rheological properties of water-based drilling fluids by using multi-walled carbon nanotube, nanosilica and glass beads," Journal of Petroleum Science and Engineering, vol. 139, pp. 264-275, 2016.

[10] E. A. Whitsitt and A. R. Barron, "Silica coated single walled carbon nanotubes," Nano Letters, vol. 3, no. 6, pp. 775-778, 2003.

[11] A. G. Ryabenko, T. V. Dorofeeva, and G. I. Zvereva, "UV-VISNIR spectroscopy study of sensitivity of single-wall carbon nanotubes to chemical processing and Van-der-Waals SWNT/SWNT interaction. Verification of the SWNT content measurements by absorption spectroscopy," Carbon, vol. 42, no. 8-9, pp. 1523-1535, 2004.

[12] H. Wang, D. L. Ho, K. I. Winey, J. E. Fischer, C. J. Glinka, and E. K. Hobbie, "Dispersing single-walled carbon nanotubes with surfactants: a small angle neutron scattering study," Nano Letters, vol. 4, no. 9, pp. 1789-1793, 2004.

[13] L. Guardia, J. I. Paredes, P. Solís-Fernández, S. Villar-Rodil, A. Martínez-Alonso, and J. M. D. Tascón, "High-throughput production of pristine graphene in an aqueous dispersion assisted by non-ionic surfactants," Carbon, vol. 49, no. 5, pp. 1653-1662, 2011.
[14] T. Hertel, V. Talalaev, K. Arnold et al., "Spectroscopy of single- and double-wall carbon nanotubes in different environments," Nano Letters, vol. 5, no. 3, pp. 511-514, 2005.

[15] B. Vigolo, A. Pénicaud, C. Coulon et al., "Macroscopic fibers and ribbons of oriented carbon nanotubes," Science, vol. 290, no. 5495, pp. 1331-1334, 2000.

[16] J. Yu, N. Grossiord, C. E. Koning, and J. Loos, "Controlling the dispersion of multi-wall carbon nanotubes in aqueous surfactant solution," Carbon, vol. 45, no. 3, pp. 618-623, 2007.

[17] L. M. Malard, M. A. Pimenta, G. Dresselhaus, and M. S. Dresselhaus, "Raman spectroscopy in graphene," Physics Reports, vol. 473, no. 5-6, pp. 51-87, 2009.

[18] K.-i. Sasaki, Y. Tokura, and T. Sogawa, "The origin of Raman D band: bonding and antibonding orbitals in graphene," Crystals, vol. 3, no. 1, pp. 120-140, 2013.

[19] J. Hodkiewicz and T. F. Scientific, "Characterizing carbon materials with Raman spectroscopy," Progress in Materials Science, vol. 50, no. 8, pp. 929-961, 2005.

[20] A. C. Ferrari, J. C. Meyer, V. Scardaci et al., "Raman spectrum of graphene and graphene layers," Physical Review Letters, vol. 97, no. 18, pp. 1-4, 2006.

[21] A. Gupta, G. Chen, P. Joshi, S. Tadigadapa, and P. C. Eklund, "Raman scattering from high-frequency phonons in supportedn-graphene layer films," Nano Letters, vol. 6, no. 12, pp. 2667-2673, 2006.

[22] M. S. Dresselhaus, A. Jorio, M. Hofmann, G. Dresselhaus, and R. Saito, "Perspectives on carbon nanotubes and graphene Raman spectroscopy," Nano Letters, vol. 10, no. 3, pp. 751758, 2010 .

[23] D. Graf, K. Ensslin, C. Stampfer, A. Jungen, C. Hierold, and L. Wirtz, "Raman imaging of graphene," Solid State Communications, vol. 143, no. 1-2, pp. 44-46, 2007.

[24] Z. Luo, Z. Ni, S. Lim et al., "Electronic structures and structural evolution of hydrogenated graphene probed by Raman spectroscopy," Journal of Physical Chemistry C, vol. 115, no. 5, pp. 1422-1427, 2011.

[25] M. Wall, "The Raman spectroscopy of graphene and the determination of layer thickness," Thermo Science, p. 5, 2011.

[26] C. Kumar, Carbon Nanomaterials, Wiley, Hoboken, NJ, USA, 2011.

[27] I. Childres, L. Jauregui, W. Park, H. Cao, and Y. Chen, "Raman spectroscopy of graphene and related materials," New Developments in Photon and Materials Research, pp. 1-20, 2013.

[28] A. Krueger, Carbon Nanomaterials and Nanotechnology, Wiley-VCH, Weinheim, Germany, 2010.

[29] I. D. Morrison and S. Ross, Colloidal Dispersions: Suspensions, Emulsions, and Foams, Wiley-Interscience, UK, 2002.

[30] M. F. Islam, E. Rojas, D. M. Bergey, A. T. Johnson, and A. G. Yodh, "High weight fraction surfactant solubilization of single-wall carbon nanotubes in water," Nano Letters, vol. 3, no. 2, pp. 269-273, 2003.

[31] S. Ridha, A. Ibrahim, R. Shahari, and S. Fonna, "Graphene nanoplatelets as high-performance filtration control material in water-based drilling fluids," IOP Conference Series: Materials Science and Engineering, vol. 352, article 012025, 2018.

[32] N.-W. Pu, C.-A. Wang, Y.-M. Liu, Y. Sung, D.-S. Wang, and M.-D. Ger, "Dispersion of graphene in aqueous solutions with different types of surfactants and the production of graphene films by spray or drop coating," Journal of the Taiwan Institute of Chemical Engineers, vol. 43, no. 1, pp. 140-146, 2012.

[33] H. Kataura, "Optical properties of single-wall carbon nanotubes,” Synthetic Metals, vol. 103, pp. 1-4, 1999. 
[34] L. Jiang, L. Gao, and J. Sun, "Production of aqueous colloidal dispersions of carbon nanotubes," Journal of Colloid and Interface Science, vol. 260, no. 1, pp. 89-94, 2003.

[35] API, Recommended Practice for Field Testing Water-Based Drilling Fluids, 2015.

[36] A. K. Sharma, A. K. Tiwari, and A. R. Dixit, "Rheological behaviour of nanofluids: a review," Renewable and Sustainable Energy Reviews, vol. 53, pp. 779-791, 2016.

[37] C. Y. Ho, S. Yusup, C. V. Soon, and M. T. Arpin, "Rheological behaviour of graphene nano-sheets in hydrogenated oil-based drilling fluid," Procedia Engineering, vol. 148, pp. 49-56, 2016.

[38] J. T. Srivatsa and M. B. Ziaja, "An experimental investigation on use of nanoparticles as fluid loss additives in a surfactantpolymer based drilling fluid," in Proceedings of the International Petroleum Technology Conference (IPTC), vol. 3, pp. 2436-2454, Bangkok, Thailand, February 2012.

[39] C. Lam and S. A. Jefferis, "Interpretation of viscometer test results for polymer support fluids," in Proceedings of the Tunneling and Underground Construction, pp. 439-449, Shanghai, China, May 2014.

[40] H.-C. Chang, B.-J. Hwang, Y.-Y. Lin, L.-J. Chen, and S.-Y. Lin, "Measurement of critical micelle concentration of nonionic surfactant solutions using impedance spectroscopy technique," Review of Scientific Instruments, vol. 69, no. 6, pp. 2514-2520, 1998.

[41] P. Yunita, S. Irawan, and D. Kania, "Evaluation of non-ionic and anionic surfactants as additives for water-based mud," Journal of the American Chemical Society, vol. 5, pp. 52-55, 2015.

[42] P. Yunita, S. Irawan, and D. Kania, "Optimization of waterbased drilling fluid using non-ionic and anionic surfactant additives," Procedia Engineering, vol. 148, pp. 1184-1190, 2016. 


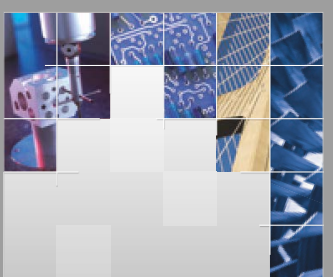

\section{Enfincering}
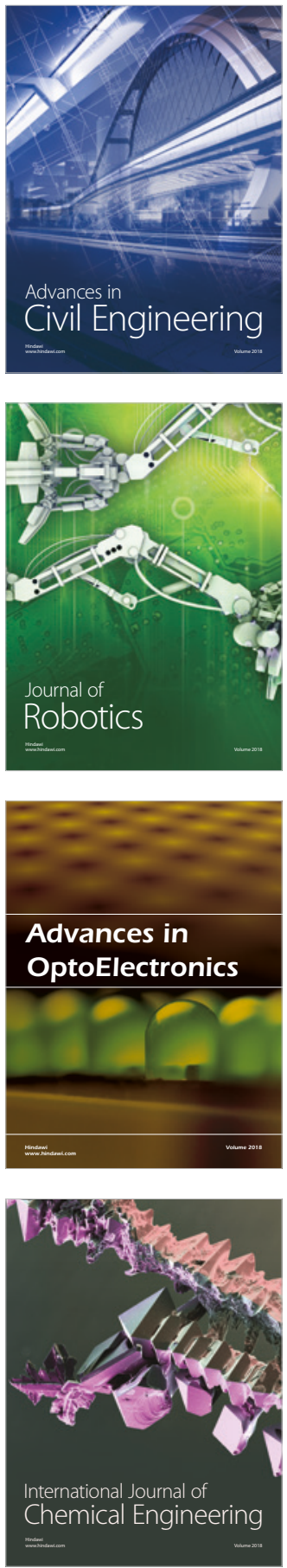

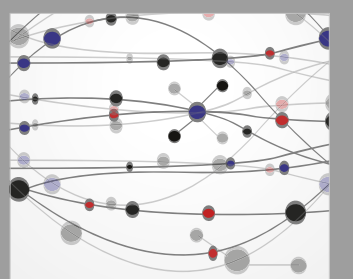

\section{Rotating \\ Machinery}

The Scientific World Journal

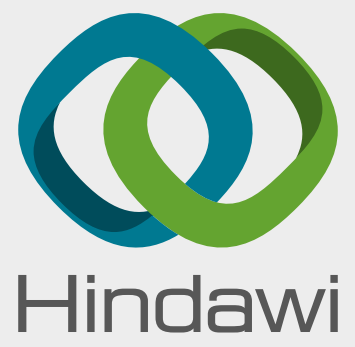

Submit your manuscripts at

www.hindawi.com
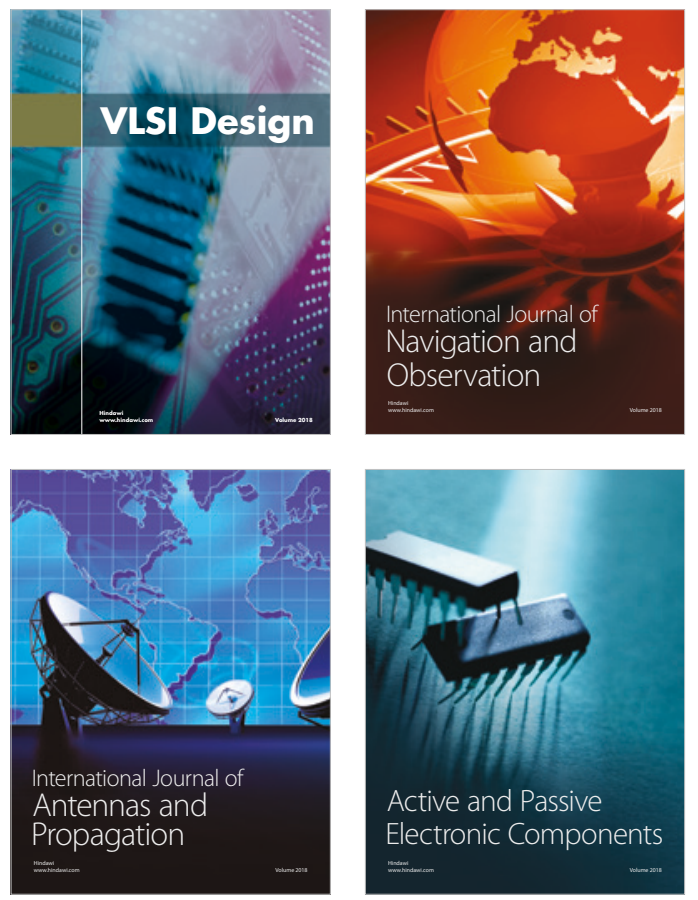
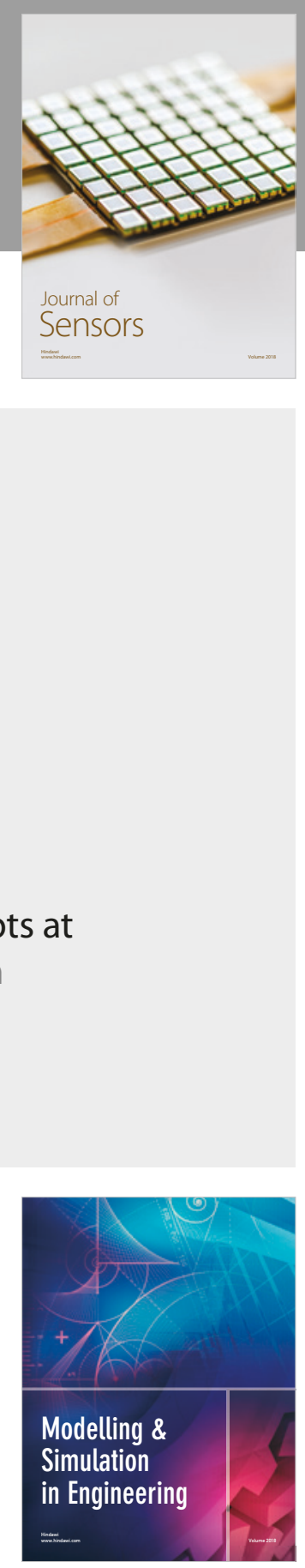

\section{Advances \\ Multimedia}
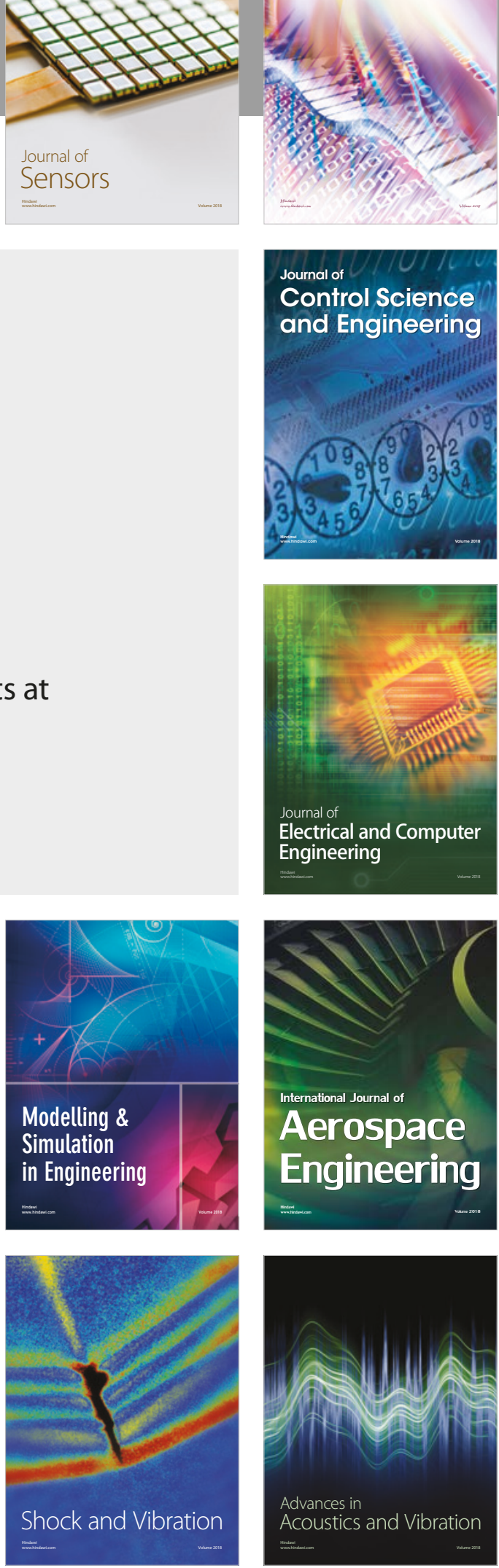